\title{
LEITURA E INTERCULTURALIDADE NO ENSINO DE ITALIANO COMO LÍNGUA ESTRANGeira no CenTro de Línguas E INTERCULTURALIDADE (CELIN) DA UFPR
}

\section{Lettura e interculturalità nell'insegnamento dell'italiano come lingua straniera presso il Centro de Línguas e Interculturalidade (Celin) dell'UFPR}

Reading and Interculturality in Teaching Italian as a Foreign Language at the UFPR Centro de Linguas e Interculturalidade (Celin)

\author{
LUCIANA LANHI BALTHAZAR * \\ BrígIDA Adele MenegattI * *
}

RESUMO: O presente artigo analisa três livros de leitura, utilizados pelos alunos do nível III (A2) no Centro de Línguas e Interculturalidade (Celin) da Universidade Federal do Paraná (UFPR). A partir da análise, propõe-se uma prova oral e uma atividade complementar online para um dos livros. Os três livros analisados são: Un Giorno Diverso, Il Manoscritto di Giotto (ambos de leitura graduada) e Alberto Moravia (livro de literatura adaptada), todos da editora Edilingua, classificados como A2-B1 segundo o Quadro Comum Europeu de Referência para Línguas. Para realizar a análise, foi considerado o contexto de uso desses livros de leitura e também o material didático utilizado pelos alunos do curso de italiano no Celin. Foram investigados os campos semânticos, os aspectos interculturais e o conteúdo linguístico dos três livros de leitura e do livro didático. A partir das conclusões, foi escolhido o livro de literatura adaptada, Alberto Moravia, e foi elaborada uma prova oral e uma atividade complementar online para esse livro, ambas apoiadas na abordagem intercultural (KRAMSCH, 1993, 2017).

PALAVRAS-CHAVE: Leitura; Interculturalidade; Língua italiana; Celin.

*Docente - Universidade Federal do Paraná

lucianallbb@hotmail.com (ORCID: 0000-0001-7159-3788)

**Mestranda em Letras - Universidade Federal do Paraná

brigidagatti@gmail.com (ORCID: 0000-0002-4079-375X)

DOI: http://dx.doi.org/10.11606/issn.2238-8281.v0i42p113-131 
ABSTRACT: Questo articolo analizza tre libri di lettura utilizzati dagli studenti di livello III (A2) presso il Centro di Lingue e Interculturalità (Celin) dell'Università Federale del Paraná (UFPR). Sulla base dell'analisi si propone un esame orale e un'attività complementare online per uno dei libri. I tre libri analizzati sono: Un Giorno Diverso, Il Manoscritto di Giotto (entrambi di lettura graduata) e Alberto Moravia (libro di letteratura adattata), tutti della casa editrice Edilingua, classificati A2-B1 secondo il Quadro Comune Europeo di Riferimento per le Lingue. Per effettuare l'analisi sono stati considerati il contesto d'uso di questi libri di lettura e anche il materiale didattico utilizzato dagli studenti del corso di italiano al Celin. Sono stati studiati i campi semantici, gli aspetti interculturali e il contenuto linguistico dei tre libri di lettura e del libro didattico. Dalle conclusioni, è stato scelto il libro di letteratura adattata, Alberto Moravia, e sono stati elaborati un esame orale e un'attività complementare online per questo libro, entrambi supportati dall'approccio interculturale (KRAMSCH, 1993, 2017).

PAROLE CHIAVE: Lettura; Interculturalità; Lingua italiana; Celin.

ABSTRACT: This article analyzes three books suggested for level III (A2) students who are enrolled at Language Center and Interculturality (Celin) from Federal University of Paraná (UFPR). Based on this analysis the article aims to offer an oral exam and a complementary online activity designed for one of the three recommended books. The three analyzed books are: Un Giorno Diverso, Il Manoscritto di Giotto (both graduated readings) and Alberto Moravia (adapted literature book), all from Edilingua publishing house and ranked as A2-B1, according to the Common European Framework of Reference for Languages. In order to carry out such analysis, the following criteria were taken into consideration: the selected reading book's context of use and the teaching material used by students who are enrolled in the Italian course at Celin. The semantic fields, the intercultural aspects and the linguistic content of the three reading books and of the textbook are researched in the analysis. Based on the results of the analysis, the book Alberto Moravia was chosen and an oral test and a complementary online activity were prepared for this book, both based on the intercultural approach (KRAMSCH, 1993, 2017).

KEYWORDS: Reading; Interculturality; Italian language; Celin. 


\section{Introdução}

O Centro de Línguas e Interculturalidade (doravante Celin) foi criado em 1995 e destinado à formação profissional e continuada dos alunos de graduação dos cursos de Letras da Universidade Federal do Paraná (UFPR). Atualmente oferece 23 cursos diferentes ${ }^{1}$, dentre eles, o de língua italiana.

O curso de italiano como língua estrangeira (LE) é composto de 8 níveis, um em cada semestre, totalizando 4 anos. A coletânea de livros didáticos utilizada durante o percurso dos 8 níveis é $A l$ dente 2 , da editora Casa delle Lingue. Além do livro didático, a coordenação de italiano sugere que os alunos do Celin leiam pelo menos um livro de leitura por semestre, ou seja, um livro de leitura para cada nível. A escolha de qual livro ler cabe aos professores junto aos alunos, dentre alguns já sugeridos pela coordenação antecipadamente. A leitura é proposta, dentre outros objetivos, também com o intuito de ser alvo de uma das avaliações orais dos alunos ao longo do curso ${ }^{3}$.

Este artigo nasce a partir de reuniões pedagógicas promovidas entre a coordenação de italiano do Celin e os pesquisadores-bolsistas, que são também licenciandos do curso de Letras Italiano-Português da UFPR, com a intenção de analisar os livros de leitura que já estavam sendo utilizados para a avaliação oral e, se necessário, substituí-los. O objetivo do grupo era também elaborar novas provas orais e atividades complementares para os alunos de italiano do Celin com os livros selecionados. Com o início da pandemia do Covid-19, em 2020, foi decidido que as atividades complementares seriam elaboradas em modo online.

Para o nível III do Celin eram sugeridos os livros de leitura graduada Un Giorno Diverso e Il Manoscritto di Giotto e o livro de literatura adaptada Alberto Moravia, todos da editora Edilingua e classificados como A2-B1, segundo o Quadro Europeu Comum de Referência para Línguas (doravante QECR). O professor do nível III, junto aos seus alunos do Celin, poderia escolher uma das três obras para trabalhar em sala de aula e realizar a prova oral que consistia, na maioria das vezes, em contar oralmente o enredo da obra. A escolha do livro de leitura deveria levar em consideração também o livro didático utilizado, ou seja, as quatro primeiras unidades do livro Al dente 2.

Para este artigo, apresentaremos algumas das análises desenvolvidas durante as reuniões pedagógicas, nas quais verificamos aspectos semânticos, interculturais e o conteúdo linguístico dos três livros de leitura e os relacionamos com o livro didático utilizado no nível III. Nosso objetivo foi escolher um livro de leitura relacionado com aspectos interculturais e conteúdos

$1 \quad$ Fonte: http://www.celin.ufpr.br/, acesso em 14/09/2020.

2 A coletânea $\mathrm{Al}$ dente é composta, atualmente, por 4 livros: Al dente 1 (A1) utilizado no Celin para os níveis I e II, Al dente 2 (A2) para os níveis III e IV, o Al dente 3 (B1) para os níveis V e VI, e o Al dente 4 (B2) para os níveis VII e VIII.

3 Atualmente a avaliação do aluno no curso de italiano do Celin é feita através da média de 9 atividades: 2 provas orais (leitura de 1 livro e 1 seminário apresentados pelos alunos), 2 provas escritas e 5 produções escritas. 
linguísticos estudados durante o III nível do Celin, para, dessa forma, promover uma avaliação mais contextualizada e significativa.

Em relação à fundamentação teórica deste artigo, primeiramente definimos o que entendemos por 'literatura adaptada' e 'leitura graduada'. Em seguida, verificamos nos estudos da área, vantagens e desvantagens do uso de literatura adaptada e leitura graduada levando em consideração também o contexto no qual esses livros de leitura são utilizados, ou seja, o nível III do italiano no Centro de Línguas da Universidade Federal do Paraná. Posteriormente, apontamos conceitos que nos fundamentam na escolha da abordagem intercultural (KRAMSCH, 1993, 2017), utilizada para a elaboração da prova oral e da atividade complementar online.

Para finalizar o artigo, apresentamos algumas conclusões do longo processo de produção de uma prova oral e de uma atividade online a partir da análise dos materiais, e também do trabalho de formação inicial de professores de italiano que é realizado no Celin.

Incluímos nos anexos a prova oral (Anexo) e disponibilizamos o link de acesso à atividade complementar online.

\section{Fundamentação teórica}

\subsection{Literatura adaptada $x$ leitura graduada: definição de conceitos}

A primeira conceitualização importante para o presente estudo é definir o que entendemos por literatura adaptada e leitura graduada.

O primeiro termo refere-se a livros que tenham sido, como o próprio nome já diz, adaptados ao leitor. No caso do livro Alberto Moravia, a adaptação foi feita pela editora para facilitar a leitura de 10 obras do autor italiano por parte dos estudantes de italiano como LE, público-alvo da editora em questão. A adaptação consiste numa seleção de excertos da obra original sem alteração alguma da língua utilizada pelo autor. Isso traduz-se numa diminuição significativa de páginas em relação à obra original. Por exemplo, o romance publicado em 1929, Gli indifferenti, tem aproximadamente 324 páginas (Editora Bompiani, 2016), mas o livro de literatura adaptada Alberto Moravia dedica 3 páginas (Editora Edilingua, 2014) para apresentá-lo. O segundo romance de Moravia no livro de literatura adaptada, Agostino, é apresentado em 4 páginas, enquanto o original conta com aproximadamente 182 páginas (Editora Bompiani, 2014). E o mesmo se dá nas outras 8 obras de Moravia: Racconti romani: Il picche nicche - 5 páginas, Racconti romani: Il Pignolo - 5 páginas, Racconti romani: La ciociara - 7 páginas, Racconti romani: Le sue giornate - 7 páginas, Racconti romani: La raccomandazione - 7 páginas, Racconti romani: Quant'è caro - 6 páginas, La ciociara - 3 páginas e La noia - 4 páginas. Ou seja, o livro de literatura adaptada Alberto Moravia apresenta 10 grandes obras do consagrado autor italiano em pouco mais de 50 páginas. Cada obra é introduzida por uma contextualização do enredo. Além disso, é apresentado um glossário em italiano no rodapé de quase todas as páginas para auxiliar o aluno na compreensão de algumas palavras. 
Outras características do material são: a) é acompanhado por CD com o audiolivro, b) existe uma biografia do autor e as datas de publicação das obras mais relevantes após a introdução e, c) apresenta atividades para cada uma das 10 obras (capítulos) e suas respectivas respostas corretas, ao final do material.

Já o termo "leitura graduada" é usado, no presente artigo, para definir livros produzidos com o objetivo de ensinar a língua e a cultura. De fato, na introdução dos dois livros de leitura graduada analisados, Il Manoscritto di Giotto e Un giorno diverso (Editora Edilingua, 2012) é afirmado que o objetivo de tais materiais é:

por um lado, satisfazer o prazer da leitura com um texto narrativo não longo demais, nem difícil de entender, e, por outro lado, oferecer uma maneira para adquirir um maior conhecimento da língua e da cultura italiana4 ${ }^{4}$ (ODDO, 2012, p. 4, tradução nossa)

O mesmo texto de introdução é usado no outro livro de leitura graduada, Un giorno diverso (mesma editora e mesmo ano de publicação), reforçando portanto a ideia de que tais livros de leitura graduada são escritos para "ensinar" a língua e a cultura italiana aos alunos estrangeiros que estudam italiano como LE.

Vejamos outras características dos materiais: a) os autores são professores de italiano como LE; b) o material tem um CD com o audiolivro; c) existem notas de rodapé com explicações de algumas palavras, d) todo capítulo é introduzido com perguntas para "manter viva a motivação do estudante " (ODDO, 2012, p. 4, tradução nossa); e) ao final do livro existem algumas atividades e, em seguida, os respectivos gabaritos; f) apresentam na capa do livro a indicação de nível de acordo com o QECR (ambos são destinados ao nível A2-B1).

Após a definição de "literatura adaptada" e "leitura graduada", é necessário refletir sobre o contexto no qual tais livros são utilizados e entender algumas vantagens e desvantagens de seu uso.

\subsection{Literatura adaptada e leitura graduada em sala de aula de italiano como LE no Celin}

Nesta seção, tentaremos situar o contexto de uso dos livros de leitura investigados e, para tanto, apresentaremos também algumas vantagens e desvantagens desses materiais.

Alonso (2011), após fazer uma atenta análise da literatura sobre o uso de textos literários adaptados para o ensino de LE, cita O’Neill (1998) para elencar algumas vantagens do seu uso, dentre elas: "a acessibilidade e economia de tempo em sala de aula e a capacidade de promover não apenas a leitura, mas produções linguísticas que levem a estudos mais aprofundados sobre a LE” (p.30).

$4 \quad$ No original: "da una parte soddisfare il piacere della lettura con un testo narrativo non troppo esteso né difficile da comprendere e dall'altra parte offrire un mezzo per raggiungere una maggiore conoscenza della lingua e della cultura italiana" (ODDO, 2012, p. 4).

$5 \quad$ No original: "mantenere viva la motivazione dello studente" (ODDO, 2012, p. 4). 
De fato, a acessibilidade é um ponto que merece ser destacado. Se pensarmos no contexto de ensino de italiano desta pesquisa, é difícil imaginar, com raras e felizes exceções, que alunos do terceiro nível (A2) teriam acesso à leitura de obras de Alberto Moravia em língua italiana. Embora ele seja um autor consagrado na literatura italiana e com obras traduzidas para o português, seus livros em italiano não são facilmente encontrados no Brasil ${ }^{6}$ e exigem conhecimento de aspectos culturais italianos para serem bem compreendidos. Portanto, proporcionar um primeiro contato a tais obras, mesmo que por meio de pequenos trechos e de forma fragmentada, pode ser uma oportunidade para introduzir os alunos à intrigante literatura de Moravia.

A economia de tempo também é uma vantagem no uso de literatura adaptada em sala de aula e não pode ser desconsiderada. Se pensarmos que a carga horária do curso semestral do Celin é de 60 horas, fica mais fácil perceber como o uso de pequenos excertos de uma obra pode ser vantajoso. Em razão do tempo, seria impossível ler uma obra completa de um autor como Moravia em sala de aula e conseguir manter o programa já estabelecido para o nível III em apenas 60 horas.

Por fim, a promoção da leitura e de estudos mais aprofundados em LE é uma outra característica desse tipo de leitura que vale a pena levar em consideração para o presente contexto. Incentivar os alunos a ler em italiano já é, de fato, um passo importante para o processo de aprendizagem. E ainda, a promoção de estudos mais aprofundados não só no nível linguístico, mas sobretudo do contexto social, econômico e cultural no qual a obra italiana foi escrita é uma oportunidade única de desenvolvimento da competência sociocultural para os aprendizes. Além disso, a leitura de alguns trechos de obras relevantes de Moravia pode despertar o interesse do aluno em ler a obra completa.

Uma desvantagem do uso da literatura adaptada, no caso do livro analisado, é a apresentação parcial de obras com um potencial extraordinário. O romance $I$ racconti, por exemplo, vencedor do prêmio literário Strega $a^{7}$, é somente um exemplo da grandiosidade da literatura do autor. Seria possível elaborar um curso inteiro de italiano através das suas obras. Neste sentido, a proposta do livro de literatura adaptada Alberto Moravia pode se demonstrar simplista e rasa.

As vantagens apontadas pelos autores dos dois livros de leitura graduada analisados, Fulvia Oddo e Marco Dominici, como já mencionado, é que este tipo de leitura facilita o acesso à língua italiana por não ser "longo", nem "difícil". Entretanto, a ideia de que somente níveis mais avançados de língua poderiam usar literatura, mesmo que amplamente difundida entre professores e alunos, parece não ser totalmente verídica. Como defende Santoro (2007), ainda existe a lógica errônea da necessidade de um profundo conhecimento da língua estrangeira entendida como "fácil", para, somente posteriormente, ter acesso à literatura, considerada a parte "difícil". Acreditamos que essa lógica, além de simplificar a complexidade da aprendizagem de uma língua estrangeira, ainda ignora o potencial do texto literário na aprendizagem já em níveis iniciais, como exemplificaremos mais adiante com a apresentação de uma atividade complementar online elaborada a partir do texto autêntico de Moravia.

$6 \quad$ Na biblioteca do Setor de Humanas da UFPR, por exemplo, não existe nenhum exemplar da obra de Moravia. 7 Maior prêmio da literatura italiana, realizado desde 1947, maiores informações: https://www.premiostrega.it/ 
Outro ponto crítico do uso de livros de leitura graduada é a exaltação do conteúdo linguístico em detrimento de todo o potencial que um texto literário pode apresentar. A necessidade de levar a utilizar uma língua "fácil" acaba por apresentar uma língua artificial, um modelo forçado e forjado de língua italiana. Com efeito, segundo Santoro (2007), o mesmo acontece com a literatura em livros didáticos: esse tipo de ensino desconsidera toda a potencialidade da literatura para exaltar apenas o conteúdo linguístico. Nas suas palavras:

A consequência é que, num movimento contrário ao da ênfase na literatura, o aspecto mais especificamente literário (estético, múltiplo, denso) do texto é sacrificado para que se alcance a compreensão do enredo, da mensagem, do referente, da denotação, sem que se indique ao aprendiz quais são os caminhos por meio dos quais é gerado o sentido e sem que sejam exploradas as possíveis interpretações. (SANTORO, 2007, p.21)

Com efeito, ignorar outras "possíveis interpretações", como aponta a autora, foi uma das consequências mais evidentes do uso de leitura graduada nas aulas de italiano no Celin. Durante as discussões realizadas nas reuniões pedagógicas com os professores de italiano do Centro, alguns deles afirmaram que quando utilizavam tais livros para auxiliar na prova oral, os alunos ficavam limitados à simples descrição do enredo. Segundo eles, era difícil proporcionar outros debates e diálogos provenientes dos livros de leitura graduada. Após o alcance da compreensão do enredo, como alerta Santoro (2007), as discussões se exauriam.

Para terminar esta seção, é relevante frisar que acreditamos em todo o potencial que envolve o uso da literatura em sala de aula de italiano como língua estrangeira no Celin, mesmo em níveis iniciais. Para nós, a literatura em sala de aula, mesmo a literatura adaptada, pode proporcionar muito mais aos alunos que a simples exploração de conhecimentos linguísticos. Um exemplo desse potencial é o acesso às diferentes manifestações sociais, culturais, econômicas e emocionais de outros países que, se comparadas àquelas brasileiras, podem promover o desenvolvimento da competência intercultural, tema da próxima seção deste artigo.

Por último, vale ressaltar que nem toda a fundamentação teórica apresentada neste artigo refere-se exclusivamente ao uso da literatura adaptada. De fato, não encontramos estudos que analisem o uso de livros de literatura adaptada referente somente ao ensino de italiano como LE. Entretanto, mesmo em língua inglesa, Albertino (2008, apud ALONSO, 2011) afirma que existe uma "escassez de estudos empíricos que investigam a recepção a textos literários adaptados". Com efeito, percebemos que a maior parte dos estudos envolvendo ensino de LE e literatura referem-se aos efeitos do uso da literatura (não adaptada) para o ensino de LE, entretanto, como já demonstrado nesta seção, existem pontos de interseção nas análises.

\subsection{Abordagem intercultural}

Normalmente os currículos escolares separam a aula de língua da aula de literatura, tanto na língua materna do aluno como na LE, esperando que os professores não ensinem nada além 
da língua. Por isso, muitas escolas contratam um professor nativo, para que este possa ensinar a cultura da língua ao aluno, porém o falante nativo não servirá como modelo para seu aluno, que, mesmo estudando a LE, não se tornará um nativo (KRAMSCH, 2017) ${ }^{8}$.

Kramsch afirma que o signo linguístico vai muito além da definição dicionarizada, pois a autora defende que a língua representa a realidade social, assim como as identidades sociais e culturais de um determinado grupo.

Nos primeiros anos do século XXI, a globalização, a web e as tecnologias da informação e comunicação mudaram a forma de estudar LE, porém ainda não mudaram a forma de estudar e ensinar cultura (KRAMSCH, 2017). Na era pós-moderna, com a globalização, a cultura não está mais limitada ao território de uma nação-estado e à sua história. É possível compreendê-la como um processo discursivo dinâmico, construído e reconstruído de várias formas por indivíduos com suas subjetividades e interpretações da história, como afirma Blommaert (2005). O autor acrescenta que o século XXI é o período de interesses ecológicos globais, portanto, a cultura não pode mais ser interpretada somente como comportamentos e eventos, mas sim como o significado que um grupo social dá às práticas discursivas que compartilham em um determinado espaço e tempo, durante a vida histórica deste grupo.

Assim, para aprender sobre uma cultura é preciso estar ciente sobre as próprias práticas discursivas. Pois a visão pós-moderna de cultura preserva a historicidade das comunidades de fala e respeita a subjetividade de falantes e escritores (KRAMSCH, 2017).

Ao entender cultura a partir dessa perspectiva, o ensino da LE e da cultura de um (ou mais) grupo social se torna indissociável e permite: 1) maior compreensão dos próprios valores culturais; 2) o acesso a bens culturais da humanidade em outras partes do mundo; 3) a valorização das culturas presentes no Brasil; 4) o desenvolvimento da empatia e solidariedade para com aqueles que sofrem discriminação (GIMENEZ, 2008).

A abordagem intercultural não se limita a transferir noções culturais, mas inclui: 1) a reflexão sobre a cultura nativa $(\mathrm{CN})$ e a cultura-alvo $(\mathrm{CA}) ; 2$ ) o ensino de cultura como um processo interpessoal; 3) o ensino de cultura como diferença e não necessariamente como características nacionais; 4) o cruzamento de fronteiras disciplinares (KRAMSCH, 1993).

Para que essa abordagem seja viável, Kramsch (1993) propõe: 1) reconstruir o contexto de produção e recepção do texto dentro da cultura estrangeira; 2) examinar as percepções que a $\mathrm{CN}$ e a CA têm uma da outra para, por fim; 3) promover diálogos que poderiam levar à mudança.

Portanto, percebemos que, segundo os critérios estabelecidos pela autora, um falante interculturalmente competente possui, além de competência linguística, consciência sociolinguística.

Para aplicar a abordagem intercultural ao ensino de LE, Gimenez (2008) defende integrá-lo às fases iniciais, sem deixá-lo para quando o aluno estiver mais proficiente. Crozet, Liddicoat e Lo Bianco (1999) afirmam que o ensino intercultural inclui a exploração das diferenças,

$8 \quad$ Existe um amplo arcabouço teórico sobre a abordagem intercultural. Selecionamos aqui Kramsch (1993, 2017) e Gimenez (2008), pois foram os textos lidos durante as reuniões pedagógicas. 
possibilitando a sensibilização para o Outro, permitindo assim pensar sobre a própria visão do mundo e, sobretudo, tolerar as diferenças.

A abordagem intercultural foi o embasamento teórico para a criação tanto da prova oral (Anexo), quanto da atividade complementar online, elaboradas após a análise dos materiais.

Seus construtos teóricos preconizam que "a capacidade de compreender e de interagir de maneira efetiva com pessoas de diferentes origens culturais, permite que se estabeleça um diálogo entre as duas culturas, prevenindo os ruídos na comunicação" (BACCIN, 2012, p. 19). De fato, acreditamos na necessidade de interação e diálogos entre as culturas para evitar desentendimentos entre os falantes.

A nosso ver, o uso de livros de literatura em sala de aula de italiano como LE é uma ótima maneira de aproximar os aprendizes de italiano não só da língua autêntica, mas, sobretudo, oportuniza a percepção de como os autores descrevem modos de viver em sociedade, jeito de se vestir, se alimentar, se relacionar, etc.

Aprender uma nova língua não é somente aprender estruturas gramaticais e léxico, mas compreende, inclusive, entender em qual contexto estas estruturas estão inseridas, para que, assim, a comunicação possa de fato acontecer.

Ler livros autênticos e não artificiais oportuniza contrastar ambas as culturas, a CN com a CA. Essa reflexão entre a percepção de duas (ou mais) culturas diferentes, além de fazer com que o aluno compreenda a CA, também auxilia a observação da $\mathrm{CN}$ por meio de questionamentos, análises, etc.

Por outro lado, a construção de uma língua artificial, promovida pelos materiais não autênticos, como a encontrada em livros de leitura graduada, por exemplo, poderia dificultar a observação destes aspectos culturais e, consequentemente, atrapalhar na comunicação autêntica com os falantes de outra língua.

A interculturalidade quebra paradigmas e propicia maior entendimento e conhecimento da própria cultura e de costumes habituais no país de língua materna do falante.

\section{Análise dos livros de leitura}

A análise foi realizada por meio de uma comparação entre o livro didático (Al dente 2, Editora Casa delle Lingue) e os três livros de leitura (Un giorno diverso, Il manoscritto di Giotto e Alberto Moravia, todos os três da Editora Edilingua) usados no nível III do Celin.

A comparação levou em consideração três aspectos: 1) campo semântico; 2) interculturalidade; 3 ) conteúdo linguístico.

O objetivo de incluir o Al dente 2 na análise, como já mencionado, foi criar uma relação entre o conteúdo de todo o semestre do nível III com a leitura do livro, para, somente depois, dispondo de vários critérios de análise, escolher o livro de leitura mais adequado para o semestre.

O primeiro aspecto verificado foi o léxico (Quadro 1), que tem um papel importante no processo de aprendizagem de uma LE, pois é parte fundamental para a compreensão de um texto. 
Quadro 1 - Campos semânticos presentes nos livros analisados

\begin{tabular}{|c|c|c|c|}
\hline $\begin{array}{l}\text { Campo semântico } \\
\text { das unidades } 1 \text { a } 4 \\
\text { do livro } \text { Al dente } 2^{9}\end{array}$ & Un giorno diverso & $\begin{array}{c}\text { Il manoscritto di } \\
\text { Giotto }\end{array}$ & Alberto Moravia ${ }^{10}$ \\
\hline $\begin{array}{l}\text { Gosto e interesses } \\
\text { pessoais; Adjetivos } \\
\text { para descrever perso- } \\
\text { nalidade e estado } \\
\text { de humor; Cores; } \\
\text { Casa; Decoração; } \\
\text { Trabalho; Sistema } \\
\text { educativo e socie- } \\
\text { dade; Trabalhos } \\
\text { domésticos; Equi- } \\
\text { pamentos e objetos; } \\
\text { Consertos de objetos } \\
\text { domésticos; Expres- } \\
\text { sões para: acusar, } \\
\text { rejeitar, justificar e se } \\
\text { desculpar. }\end{array}$ & $\begin{array}{l}\text { Casa; Vestuário; Ca- } \\
\text { feteria; Comércio. }\end{array}$ & Casa; Biblioteca. & $\begin{array}{l}\text { Adjetivos para des- } \\
\text { crever personalidade } \\
\text { e estado de humor; } \\
\text { Férias de verão na } \\
\text { praia; Festividades } \\
\text { natalinas e ano novo; } \\
\text { Papelaria; Viagem } \\
\text { de carro; Casa; } \\
\text { Cafeteria; Escritório; } \\
\text { Trabalho. }\end{array}$ \\
\hline
\end{tabular}

Fonte: Autoria própria (2020).

Ao observar os campos semânticos identificados, verificamos que o único presente em todos os livros é o da 'casa'. Com exceção deste, os outros campos semânticos dos livros Un giorno diverso e Il manoscritto di Giotto não estão no livro Al dente 2 (vestuário, cafeteria, comércio e biblioteca).

Por outro lado, encontramos no livro Alberto Moravia outros três campos semânticos ('adjetivos para descrever personalidade e estado de humor' e 'trabalho'), que estão também presentes no livro Al dente 2. Tal observação nos faz concluir que o terceiro livro de leitura analisado (Alberto Moravia) parece apresentar uma variedade de palavras mais próximas àquelas do Al dente 2, desta forma, os alunos já poderão estar mais familiarizados com o léxico.

O segundo aspecto é a interculturalidade, considerada fundamental para que o aluno possa se comunicar no ambiente social estudado, como já mencionado na fundamentação teórica deste artigo. Nesta análise (Quadro 2), faremos um elenco de alguns assuntos dos quatro livros

9 Os campos semânticos aqui apresentados foram selecionados pelos próprios autores no sumário do livro na seção Léxico (Lessico).

10 Diferentemente do que aconteceu nos outros livros, a análise dos campos semânticos de Alberto Moravia foi mais complexa, já que o texto não foi criado com o objetivo de ensinar LE. Os campos semânticos não foram colocados em primeiro plano pelo autor e não são explícitos. 
que podem oferecer, segundo as autoras deste artigo, uma oportunidade de reflexão sobre os aspectos culturais do Brasil e da Itália.

Quadro 2 - Aspectos interculturais presentes nos livros analisados

\begin{tabular}{|c|c|c|c|}
\hline $\begin{array}{l}\text { Aspectos intercultu- } \\
\text { rais das unidades } 1 \text { a } \\
4 \text { do livro } \text { Al dente } 2^{11}\end{array}$ & Un giorno diverso & $\begin{array}{l}\text { Il manoscritto di } \\
\text { Giotto }\end{array}$ & Alberto Moravia \\
\hline $\begin{array}{l}\text { Patrimônio histórico, } \\
\text { artístico e cultural } \\
\text { da Itália; Objetos } \\
\text { importantes na vida } \\
\text { cotidiana dos italia- } \\
\text { nos; Design italiano, } \\
\text { Estilo e decoração; } \\
\text { Escola italiana, Moda } \\
\text { italiana; Produtos } \\
\text { artesanais italianos. }\end{array}$ & $\begin{array}{l}\text { Café da manhã na } \\
\text { cafeteria; Moda } \\
\text { italiana. }\end{array}$ & $\begin{array}{l}\text { Patrimônio artístico } \\
\text { italiano; Expressões } \\
\text { italianas. }\end{array}$ & $\begin{array}{l}\text { Férias de verão na } \\
\text { Itália; Festividades } \\
\text { italianas; Objetos } \\
\text { importantes na } \\
\text { vida cotidiana dos } \\
\text { italianos; Produtos } \\
\text { artesanais italianos; } \\
\text { Vento } \text { scirocco }^{12} \text {; } \\
\text { Itália durante a } 2^{\text {a }} \\
\text { Guerra Mundial; } \\
\text { Trabalho na Itália; } \\
\text { Amizade; Palavras } \\
\text { e expressões típicas } \\
\text { italianas. }\end{array}$ \\
\hline
\end{tabular}

Fonte: Autoria própria (2020).

É possível observar que os aspectos interculturais presentes no livro Al Dente 2 (Unidade 1 a 4) que permitem promover diálogo e reflexão sobre a $\mathrm{CN}$ e a CA e que estão presentes nos livros são: "moda italiana" em Un giorno diverso; "patrimônio artístico italiano" em Manoscritto di Giotto; "objetos importantes na vida cotidiana dos italianos" e "produtos artesanais italianos" em Alberto Moravia. Ou seja, nos dois primeiros livros (Un giorno diverso e Il manoscritto di Giotto) apenas um aspecto intercultural coincide com Al dente 2, enquanto no livro Alberto Moravia encontramos dois aspectos interculturais também presentes no Al dente 2.

Kramsch (2017) defende que a língua representa a realidade social, assim como as identidades sociais e culturais de um determinado grupo. Portanto, ao analisarmos os aspectos interculturais, estamos verificando a oportunidade de apresentar uma situação sociocultural autêntica e cultural para que o aluno possa refletir na sua $\mathrm{CN}$ e aprender mais sobre ela, por meio do estudo e conhecimento adquirido sobre a CA. Quanto a isso, Alberto Moravia, apesar de ter coinci-

11 Os campos semânticos aqui apresentados foram selecionados pelos próprios autores no sumário do livro na seção Cultura.

12 Vento quente e úmido proveniente do sudeste. 
dido somente com dois aspectos interculturais citados no livro Al dente 2, oferece inúmeras oportunidades de diálogo sobre a $\mathrm{CN}$ e a CA porque um tema frequente nas obras de Moravia é a crise moral do século XX, caracterizada pela hipocrisia das relações sociais, especialmente na classe burguesa, e a incapacidade dos homens de encontrar a felicidade (CERNIGLIARO, 2016). Portanto, Alberto Moravia oportuniza a discussão, a análise e a reflexão sobre a sociedade italiana, dando a possibilidade ao leitor de repensar mais criticamente também sobre a sociedade na qual vivemos.

O terceiro aspecto verificado foi o conteúdo gramatical, reportado no quadro a seguir (Quadro 3), que apresenta três colunas: na primeira coluna, os conteúdos gramaticais presentes no livro Al dente 2 e, nas colunas seguintes, exemplos de frases, palavras ou expressões, extraídas dos três livros envolvidos nessa pesquisa, que utilizam tal conteúdo gramatical.

Quadro 3 - Conteúdo gramatical dos livros analisados

\begin{tabular}{|c|c|c|c|}
\hline $\begin{array}{l}\text { Conteúdo gramati- } \\
\text { cal das unidades } 1 \text { a } \\
4 \text { do livro } \text { Al dente } 2^{13}\end{array}$ & $\begin{array}{c}\text { Frases extraídas de } \\
\text { Un giorno diverso }\end{array}$ & $\begin{array}{c}\text { Frases extraídas } \\
\text { de } \text { Il manoscritto di } \\
\text { Giotto } \\
\end{array}$ & $\begin{array}{c}\text { Frases extraídas de } \\
\text { Alberto Moravia }\end{array}$ \\
\hline $\begin{array}{l}\text { 1. Pronomi } \\
\text { diretti }\end{array}$ & & La studio & La guardano \\
\hline 2. Ne partitivo & & & Ne avrà cinque \\
\hline $\begin{array}{ll}\text { 3. } & \text { Ce }+ \text { prono- } \\
& \text { mi diretti }\end{array}$ & & & Ce n'era uno libero \\
\hline $\begin{array}{l}\text { 4. L'infinito } \\
\text { passato }\end{array}$ & & Dopo aver letto & $\begin{array}{l}\text { Dopo aver gettato } \\
\text { un'occhiata }\end{array}$ \\
\hline $\begin{array}{l}\text { 5. Prima di/ } \\
\text { Dopo di }\end{array}$ & Prima di tutto & & \\
\hline 6. Gli indefiniti & & $\begin{array}{l}\text { Nessuno / Ognuno / } \\
\text { Qualche }\end{array}$ & Qualcuno / Qualche \\
\hline $\begin{array}{l}\text { 7. Essere / } \\
\text { Esserci }\end{array}$ & Non c'è più & $\begin{array}{l}\text { C'è Armando/ Non } \\
\text { c'era nessuno }\end{array}$ & $\begin{array}{l}\text { C'è stato un coro/ } \\
\text { C'era una signoral } \\
\text { c'è una cosa }\end{array}$ \\
\hline $\begin{array}{l}\text { 8. Il passato } \\
\text { prossimo }\end{array}$ & $\grave{E}$ successo & $\grave{E}$ stata proprio lei & $\begin{array}{l}\text { Sono uscito con il } \\
\text { diavolo addosso }\end{array}$ \\
\hline 9. L'imperfetto & & Era dentro & $\begin{array}{l}\text { Uscivano tutte le } \\
\text { mattine }\end{array}$ \\
\hline
\end{tabular}

13 Os campos semânticos aqui apresentados foram selecionados pelos próprios autores no sumário do livro na seção Grammatica. 


\begin{tabular}{|c|c|c|c|c|}
\hline & $\begin{array}{l}\text { L'imperfetto } \\
+ \text { passato } \\
\text { prossimo }\end{array}$ & & $\begin{array}{l}\text { Chi ha rubato } \\
\text { doveva conoscere } \\
\text { bene }\end{array}$ & $\begin{array}{l}\text { Oggetti che volavano } \\
\text { dalle finestre / } \\
\text { Siamo tornati a casa }\end{array}$ \\
\hline 11. & $\begin{array}{l}\text { Il contrasto: } \\
\text { presente } \\
\text { / passato } \\
\text { prossimo }\end{array}$ & $\begin{array}{l}\text { Si fa / Ha fatto la } \\
\text { barba }\end{array}$ & $\begin{array}{l}\grave{E} \text { appena arrivato, } \\
\text { sembra prezioso }\end{array}$ & $\begin{array}{l}\text { Ho fatto tutti } i \\
\text { Lungoteveri / Arrivo, } \\
\text { scendo, suono }\end{array}$ \\
\hline 12. & $\begin{array}{l}\text { I compara- } \\
\text { tivi }\end{array}$ & & $\begin{array}{l}\text { Una delle biblioteche } \\
\text { più importanti del } \\
\text { mondo }\end{array}$ & Più vecchio di lei \\
\hline & $\begin{array}{l}\text { Stare }+ \\
\text { gerundio }\end{array}$ & & & Sta imparando \\
\hline 14. & $\begin{array}{l}\text { I pronomi } \\
\text { con gli } \\
\text { infiniti }\end{array}$ & Non disturbarli & Catalogarli/ Darmi & $\begin{array}{l}\text { Conservarlo/ } \\
\text { Portarlo }\end{array}$ \\
\hline 15. & $\begin{array}{l}\text { Passato } \\
\text { prossimo } \\
+ \text { Pronome } \\
\text { diretto e 'ne, }\end{array}$ & & Chi l'ha fatto & $\begin{array}{l}\text { Li ho lasciati salire / } \\
\text { Gliene ho dette tante }\end{array}$ \\
\hline & $\begin{array}{l}\text { Condiziona- } \\
\text { le Presente }\end{array}$ & & $\begin{array}{l}\text { Dovresti venire / } \\
\text { Dovrebbe fare }\end{array}$ & $\begin{array}{l}\text { Dovremmo portare / } \\
\text { Ti farei }\end{array}$ \\
\hline 17. & $\begin{array}{l}\text { Gli indicato- } \\
\text { ri temporali }\end{array}$ & $\begin{array}{l}\text { Dopo/Poi/ Ogni } \\
\text { giorno/Adesso/Poco } \\
\text { Dopo }\end{array}$ & Poi/ Prima/ Dopo & $\begin{array}{l}\text { Sempre/ Prima / } \\
\text { Adesso/Dopo/Ogni } \\
\text { giorno/Poi }\end{array}$ \\
\hline & Outros: & $\begin{array}{l}\text { Riflessivi; Futuro; } \\
\text { Registro formale } \\
\text { e informale; } \\
\text { Imperativo }\end{array}$ & $\begin{array}{l}\text { Congiuntivo } \\
\text { presente; Pronomi } \\
\text { indiretti; Registro } \\
\text { formale e informale }\end{array}$ & $\begin{array}{l}\text { Pronomi indiretti; } \\
\text { Gerundio presente; } \\
\text { Futuro; Passato } \\
\text { remoto; Imperativo; } \\
\text { Riflessivi; Trapassato } \\
\text { prossimo; ecc. }\end{array}$ \\
\hline
\end{tabular}

Fonte: Autoria própria (2020).

Observa-se que, dos 17 aspectos linguísticos presentes no livro didático Al dente 2, somente 6 foram encontrados em Un giorno diverso, $13 \mathrm{em} \mathrm{Il} \mathrm{manoscritto} \mathrm{di} \mathrm{Giotto} \mathrm{e} 16$ em Alberto Moravia.

Ao observar os dados provenientes do quadro, podemos perceber que, embora no livro Alberto Moravia a língua seja utilizada para narrar estória e não apenas para ensinar a língua 
estrangeira, os pontos gramaticais estão mais presentes que nos outros dois livros. Isso reforçou ainda mais a escolha desse livro para a produção da prova e da atividade complementar, pois, além de apresentar unidades lexicais mais estudadas pelos alunos e pontos apropriados para debates interculturais, faz uso de todas as estruturas linguísticas do programa em contexto comunicativo.

Portanto, após a análise dos três aspectos selecionados nesta pesquisa, resultou que o livro Alberto Moravia seria o mais adequado para ser lido pelo nível III do Celin, pois possui mais aspectos lexicais, interculturais e gramaticais estudados pelos alunos durante o semestre letivo.

\section{Apresentação da prova oral e da atividade complementar online do livro Alberto Moravia}

Após a análise e a seleção do livro Alberto Moravia, foram elaboradas uma prova oral e uma atividade online.

Para a prova oral (Anexo), todas as questões solicitam que os alunos realizem atividades de produção oral individual e em grupos. Com o objetivo de despertar o interesse dos alunos pela leitura do livro, no início da prova é apresentado um vídeo onde Moravia é entrevistado por Pasolini. Em seguida, o(a) professor(a) apresenta brevemente o autor e distribui um capítulo/ história para cada aluno. É sugerido que as provas sejam realizadas em 5 dias, cada uma com a duração de 30 minutos, exceto a prova 3 que deveria durar 90 minutos por se tratar de 6 capítulos extraídos do mesmo livro I racconti romani. Cada aluno conta a história de seu capítulo a toda a classe, que, ao final, deverá contribuir com suas reflexões sobre o enredo. Para a realização da prova oral foram utilizados mais 4 vídeos com cenas de filmes realizados a partir da obra do autor: Gli indifferenti, Agostino, La Ciociara e La noia.

O objetivo é fazer o aluno relacionar o que ele leu com as cenas dos filmes das respectivas obras para aprofundar a sua visão sobre os temas de cada estória escrita por Moravia, refletir sobre a CN e a CA e poder, assim, contribuir para o desenvolvimento e a avaliação da oralidade dos alunos.

Um aspecto intercultural muito presente na prova é o conceito de moralidade e a indignação em ferir a moral, temas relevantes na obra do autor. Portanto, durante a prova, os alunos são incentivados a fazer frequentes comparações entre práticas culturais apresentadas no livro e práticas culturais brasileiras, como, por exemplo, analisar situações tidas como escandalosas por cada cultura. A atividade introdutória consiste em ouvir uma entrevista na qual o autor responde sobre a existência de situações que o escandalizam. Após assistir ao vídeo, os alunos devem responder à mesma pergunta, sendo assim encorajados a fazer reflexões interculturais entre os dois países.

A atividade complementar online ${ }^{14}$ sobre o livro Alberto Moravia é composta por 21 perguntas, cada uma delas com somente uma alternativa correta. Todas as questões são produzidas

14 Disponível em: https://docs.google.com/forms/d/11DHVfc69Ym_amNR06muwdXACQWIND8mnVcwIGFXxzxY/prefill 
a partir de textos autênticos como: cenas cinematográficas (baseadas nas estórias de Moravia), uma reportagem, fotos de célebres atores italianos e até mesmo um texto sensorial. Um bom exemplo de promover a interculturalidade é quando, na questão 4 por exemplo, após assistir a uma cena do filme Gli Indifferenti (conto presente no livro Alberto Moravia), pergunta-se ' $\mathrm{O}$ que o autor apresenta e critica nessa história?’, sendo que, as quatro alternativas são: a) A espontaneidade da burguesia durante o período fascista, b) A burguesia e toda a sua degeneração, ou seja, a classe que sempre enriqueceu às custas dos outros, c) $\mathrm{O}$ proletariado, d) $\mathrm{O}$ comportamento das pessoas da época (tradução própria)'. Essa questão, cuja resposta correta é a letra 'b', permite uma reflexão sobre aquele período italiano e sobre as diferentes realidades sociais existentes na Itália. A reflexão pode ser estendida ao próprio país, às suas classes sociais e às diferentes realidades existentes no Brasil. Trata-se de uma experiência intercultural que pode promover maior consciência crítica entre a $\mathrm{CN}$ e a $\mathrm{CA}$. As atividades foram elaboradas com foco na abordagem intercultural com o objetivo de promover diálogos e mudanças no entendimento da CN e da CA (KRAMSCH, 1993).

\section{Considerações finais}

O presente artigo fez uma análise do uso de livros de leitura utilizados no curso de italiano nível III (A2) do Celin da UFPR. Foram analisados três livros: um de literatura adaptada ( $\mathrm{Al}$ berto Moravia) e dois de leitura graduada (Il manoscritto di Giotto e Un giorno diverso). Além disso, foi verificado também o contexto no qual esses livros eram usados e o livro didático utilizado pelos alunos ( $\mathrm{Al}$ dente 2). A análise foi realizada, portanto, com quatro materiais e verificou campos semânticos, aspectos interculturais e conteúdos linguísticos.

Um dos primeiros resultados do estudo é que a literatura adaptada, comparada à leitura graduada, pode proporcionar mais oportunidades de aprendizagem porque apresenta uma língua mais autêntica, real e necessária para a comunicação. Após nossa análise, acreditamos que a literatura adaptada, para o contexto desta pesquisa, seja muito mais profícua que a leitura graduada para ensino de italiano como língua estrangeira, mesmo em níveis iniciais (A2).

Além disso, a literatura adaptada oportuniza mais discussões e reflexões interculturais. Diversos aspectos sociais, históricos, econômicos do país de referência ou pertinentes à sua língua podem ser percebidos quando os alunos leem esse tipo de material. Na leitura graduada, os aspectos interculturais, quando apresentados, tomam um ar de superficialidade, como se tivessem sido inseridos naquele contexto somente para serem percebidos pelo aluno e não porque de fato representam um país.

A análise dos livros desenvolvidos com o objetivo de 'ensinar' língua italiana parece apresentar uma língua artificial e forçada, com utilização de expressões idiomáticas ou palavras fora de contextos realísticos de uso da língua. Ou seja, a língua foge do seu uso natural de prática social, cujo objetivo é a comunicação, para se tornar uma oportunidade de aperfeiçoamento linguístico. As frases são pensadas não mais para dar sentido ao texto, mas para o uso de determinadas estruturas linguísticas. O resultado é um desastroso Frankenstein linguístico com 
enredos pobres que pouco colaboram para análises interculturais. De fato, uma das queixas dos professores de italiano do Celin que usavam livros de leitura graduada para as provas orais era que, após relatar a trama do livro lido pelos alunos, "acabava o assunto", nas palavras de um deles. Segundo os professores, para a promoção de novas conversas sobre aspectos interculturais eram necessários novos textos porque somente o livro não era suficiente.

Como já explicado, a análise dos quatro livros envolvidos nesta pesquisa foi realizada levando em consideração três aspectos: 1) campo semântico, 2) interculturalidade e 3) conteúdo linguístico. Em todos eles o livro Alberto Moravia apresentou mais aspectos em comum com $\mathrm{Al}$ dente 2. Em relação ao léxico, os campos semânticos das unidades 1-4 de Al dente 2 apresentam três pontos em comum com Alberto Moravia que são: 'adjetivos para descrever personalidade e estado de humor' e 'trabalho'. Já em relação à interculturalidade, Alberto Moravia apresenta dois aspectos ('objetos importantes na vida cotidiana dos italianos' e 'produtos artesanais italianos') que são concomitantes com aqueles de Al dente 2, além de oferecer um panorama real da sociedade com possibilidade de inúmeras análises interculturais, sobretudo em relação aos aspectos valorativos de uma sociedade. Finalmente, o aspecto no qual o livro Alberto Moravia mais se destaca é em relação ao conteúdo linguístico porque quase todos os pontos gramaticais (16 de um total de 17) das unidades didáticas 1-4 de Al dente 2 foram encontrados no livro. Ou seja, o livro Alberto Moravia é também uma excelente oportunidade para a percepção do uso de estruturas gramaticais já vistas durante o semestre.

Todo o processo que originou tal artigo, ou seja: analisar livros de leitura, encontrar critérios para a sua análise, escolher a abordagem ideal para elaborar atividades, produzir uma prova oral e uma atividade online, corrigi-las e formatá-las com um layout apropriado, foi realizado em, aproximadamente, um ano. É um dos resultados do trabalho realizado na formação de professores no curso de Letras Italiano da Universidade Federal do Paraná para seus atuais alunos e futuros professores. Tal formação objetiva que os licenciandos possam ter sua primeira experiência como professores, mas também auxilia na percepção da necessidade de reflexão crítica sobre o material apresentado aos alunos e o quanto língua, literatura e cultura estão profundamente ligados no ensino/aprendizagem de LE.

\section{Referências}

ALONSO, K. F. Clássicos adaptados no ensino de inglês: um estudo de caso das experiências dos estudantes em sala de aula. Dissertação (Mestrado em Estudos Linguísticos) -Universidade Federal de Minas Gerais, Belo Horizonte, 94 f., 2011. Disponível em: https://repositorio.ufmg.br/bitstream/1843/ LETR-8STLMU/1/1414m.pdf.

BLOMMAERT, J. Discourse. Cambridge: Cambridge University Press, 2005.

CERNIGLIARO, M. A. Alberto Moravia. Roma: Edilingua, 2014.

BACCIN, P. G. O dicionário bilíngue para aprendizes: uma ponte entre duas culturas. Tese (Livre-docência) - Faculdade de Filosofia, Letras e Ciências Humanas, Universidade de São Paulo, São Paulo, 258 f., 2012. 
DOMINICI, M. Un giorno diverso. Roma: Edilingua, 2012.

GIMENEZ, T. Eles comem cornflakes, nós comemos pão com manteiga: espaços para reflexão sobre cultura na aula de língua estrangeira. Anais do IX EPLE - Encontros de Professores de Línguas Estrangeiras. Londrina: Betel Gráfica e Editora LTDA, 2002. p. 107-114.

KRAMSCH, C. Context and culture in language teaching. Oxford: Oxford University Press, 1993.

KRAMSCH, C. Cultura no ensino de língua estrangeira. Bakhtiniana, Rev. Estud. Discurso, São Paulo, v. 12, n. 3, p. 134-152,dez. 2017. DOI: https://doi.org/10.1590/2176-457333606

CROZET, C., LIDDICOAT, A. \& LO BIANCO, J. Striving for the third place-intercultural competence through language education. Melbourne: Language Australia, 1999.

ODDO, F. Il manoscritto di Giotto. Roma: Edilingua, 2012.

SANTORO, E. Da indissociabilidade entre o ensino de língua e de literatura: uma proposta para o ensino do italiano como língua estrangeira em cursos de Letras. Tese (Doutorado em Semiótica e Linguística Geral) - Universidade de São Paulo, São Paulo, 355 f., 2007. Disponível em: https://www.teses. usp.br/teses/disponiveis/8/8139/tde-26022008-141241/pt-br.php.

Recebido em: 08/02/2021 (versão atualizada: 02/08/2021) Aprovado em: 02/11/2021

\section{ANEXO}

PROVA ORALE - LIBRO ALBERTO MORAVIA

Autrice: Brígida Adele Menegatti

Revisione: Paoletta Santoro

OBIETTIVO: Presentare l'autore italiano Alberto Moravia e le sue opere per invogliare gli alunni a leggere il libro di letteratura adattata chiamato Alberto Moravia. Inoltre, presentare attività per l'esame orale degli alunni di Celin, III livello (A2).

\section{RISCALDAMENTO}

1. Chiedi agli alunni cosa significa la parola: SCANDALIZZARSI (scriverla sulla lavagna)

2. Dopo che loro avranno risposto, conferma il significato: "Provare sdegno e risentimento per parole o fatti contrari alla morale, alla giustizia, o comunque ritenuti troppo spregiudicati e inopportuni" (Treccani).

3. Chiedi agli alunni di cosa si scandalizzano. Possono formare dei gruppi per discuterne e poi condividere le loro risposte con tutta la classe.

4. Mostra il video: Pasolini intervista Moravia (https://www.youtube.com/watch?$\mathrm{v}=3 \mathrm{iYWPTFo} 0 \mathrm{n} 8$ ). Gli alunni devono guardare il video e rispondere alla domanda: di che cosa si scandalizza Moravia e perché?

5. Gli alunni devono spiegare se sono d'accordo con ciò che Moravia ha detto. 


\section{ALBERTO MORAVIA}

1. Breve introduzione: vita e opere dell'autore

2. Nel libro ci sono 10 racconti classici di Moravia. Devono essere distribuiti uno ad ogni alunno. Nel caso ci siano più alunni che racconti, alcuni studenti lavorano in coppia.

INIZIO DELLE PROVE: Le prove sono suddivise in 5 giorni. Ogni prova dura 30 minuti, tranne la prova 3 che dura 90 minuti.

\section{GLI INDIFFERENTI}

1. Guarda il video sul libro Gli indifferenti (https://www.youtube.com/watch?v=d2Llo0PvMu0 - fino al minuto 2) e rispondi alle domande:

a. In quale periodo è stato scritto il libro Gli Indifferenti?

b. Com'è la società dell'epoca, secondo il video e la visione di Moravia?

2. L'alunno responsabile di questo racconto deve esporlo a tutta la classe, mentre questa prende appunti per fare un breve riassunto della storia in massimo 4 frasi.

3. Spiega la relazione tra il video guardato all'inizio della lezione e l'esposizione del compagno.

\section{AGOSTINO}

1. Guarda il video (https://www.youtube.com/watch?v=fxTQgyKx5LI - fino al minuto 2) e prendi appunti per rispondere alle domande:

a. Come immaginate che sia la vita di Agostino?

b. Qual è lo stato civile della mamma di Agostino?

c. Alla fine del video, cosa chiedono i ragazzi ad Agostino su sua mamma?

2. Un compagno racconta la storia Agostino mentre gli altri prendono appunti per fare un riassunto della storia in 2 max 4 frasi.

3. Spiega la relazione tra il video guardato all'inizio della lezione e il racconto fatto dal compagno.

\section{RACCONTI ROMANI: IL PICCHE NICCHE, PIGNOLO, LA CIOCIARA, LE SUE GIORNATE, LA RACCOMANDAZIONE, QUANT'È CARO}

1. Ascolta il racconto di ogni compagno e, nel frattempo, prendi appunti per fare un riassunto di una delle storie in $2 \max 4$ frasi. 
2. Scrivi cosa faresti se fossi al posto del protagonista della storia che hai scelto. Perché?

\section{LA CIOCIARA}

1. Guarda il video (https://www.youtube.com/watch?v=-bwxv4L2Tf4), prendi appunti per rispondere alle domande:

a. Chi scrive le lettere e cosa racconta nelle sue lettere?

b. Secondo il video, qual è il momento più bello della carriera di Sophia Loren e perché?

c. In quale periodo si svolge la Ciociara?

2. Un compagno racconta la storia La Ciociara mentre gli altri prendono appunti per fare un riassunto in 2 max 4 frasi.

\section{LA NOIA}

1. Guarda il video ( https://www.youtube.com/watch?v=SM6cI31qaW4 ), prendi appunti per rispondere alle domande:

a. Cosa pensi del rapporto fra protagonisti?

b. Come potresti definire il carattere di Dino, il protagonista?

2. Un compagno racconta la storia La noia mentre gli altri devono fare un riassunto della storia in 2 max 4 frasi.

3. Qual è la relazione tra il personaggio Dino del video e la storia raccontata? 